\title{
Modeling solar desalination with reverse osmosis (RO) powered by concentrating solar power (CSP) plan
}

\author{
Ahmed Remlaoui ${ }^{1, *}$, Hammou Soumia ${ }^{2}$, Bent Abdelkader Nafissa ${ }^{2}$, Driss Nehari ${ }^{1}$ \\ ${ }^{1}$ Smart Structure Laboratory, University Center of Ain-Témouchent, 46000 Ain-Témouchent, ALGERIA \\ ${ }^{2}$ Department of Mechanical Engineering, University Center of Ain-Témouchent, 46000 Ain-Témouchent, ALGERIA \\ donremlaoui@gmail.com
}

\begin{abstract}
This article deals with the desalination of seawater and brackish water, which can deal with the problem of water scarcity that threatens certain countries in the world; it is now possible to meet the demand for drinking water. Currently, among the various desalination processes, the reverse osmosis technique is the most used. Electrical energy consumption is the most attractive factor in the cost of operating seawater by reverse osmosis in desalination plants. Desalination of water by solar energy can be considered as a very important drinking water alternative. For determining the electrical energy consumption of a single reverse osmosis module, we used the System Advisor Model (SAM) to determine the technical characteristics and costs of a parabolic cylindrical installation and Reverse Osmosis System Analysis (ROSA) to obtain the electrical power of a single reverse osmosis module. The electrical power of a single module is $4101 \mathrm{KW}$; this is consistent with the manufacturer's data that this power must be between $3900 \mathrm{~kW}$ and $4300 \mathrm{KW}$. Thus, the energy consumption of the system is $4.92 \mathrm{KWh} / \mathrm{m} 3$.Thermal power produced by the solar cylindroparabolic field during the month of May has the maximum that is 208MWth, and the minimum value during the month of April, which equals 6 MWth. Electrical power produced by the plant varied between $47 \mathrm{MWe}$, and $23.8 \mathrm{MWe}$. The maximum energy was generated during the month of July (1900 MWh) with the maximum energy stored (118 MWh).
\end{abstract}

Keywords: System Advisor Model (SAM), Reverse Osmosis System Analysis (ROSA), Rankine cycle, parabolic trough power.

Received: 03/10/2019 - Accepted: 10/11/2019

\section{Introduction}

The use of seawater desalination to provide fresh drinking water is a well-established and flourishing industry. The two main technologies used are thermal desalination and Reverse Osmosis (RO) membrane filtration. The desalination of brackish water or seawater by conventional treatment units requires a large electrical energy and / or heat. Among the processes, distillation and reverse osmosis are technologies whose performance has been proven to desalinate salt water [1]. Concentrating solar power (CSP) technology is considered as one of the alternative solutions of power generation from solar energy. In this technology, sunrays are focused onto a solar receiver with the help of mirrors. The energy captured by the receiver is converted to heat or electricity through a series of process [2]. Martin et al. used a mathematical programming technique to optimize the operation of a CSP plant employing regenerative Rankine cycle for a site in Spain. [3]. A simulation model for predicting the electrical output of a $50 \mathrm{MWe}$ PTC power plant was developed by Garcia et al. [4]. The model results were compared with the experimental data of a power plant operating in Spain.

During our modeling and simulation work, we used software, SAM [5] (System Advisor Model) for the energy study of a parabolic concentrator and ROSA [6] (Reverse Osmosis System Analysis) to obtain the electrical power of a single reverse osmosis module.

The objective of this work is the technical and economic study of a parabolic plant used to produce electricity consumed by a reverse osmosis module. The results obtained make it possible to highlight the effect of the electrical energy consumption on the cost of desalination by reverse osmosis.

\section{Presentation of the solar desalination plant used}

The heat generated by a CSP plant can be utilized to produce the required electric power needed to drive the 
RO pumps [7].It has been reported that CSP/RO coupling is more efficient and requires less energy than CSP/MED coupling [8]. Fig. 1 shows a schematic diagram of a CSP/RO coupling [9].

The parabolic-cylindrical mirror-type solar power plant consists of parallel rows of long, semi-cylindrical, north-south-oriented mirrors that circle around it to follow the sun's course. The sun's rays are concentrated on a longitudinal receiver tube arranged all along the installation. Inside this tube circulates a coolant that will be used to capture and transport heat; the fluid temperature can reach up to $400^{\circ} \mathrm{C}$. The coolant heat is transmitted to the water that vaporizes, the steam produced operates a turbine, and this turbine drives the generator that produces electricity. This plant has a molten salt tank that can store heat for several hours, and thus produce electricity in the night.

The transfer fluid was chosen according to its physicochemical properties. In this study, Therminol VP1 was used because of its thermal stability up to temperatures of $400^{\circ} \mathrm{C}$. Therminol VP-1 is a hydrocarbon - based synthetic fluid consisting of a mixture of $75 \%$ diphenyl oxide $\left(\mathrm{C}_{12} \mathrm{H}_{10} \mathrm{OH}\right)$ and $25 \%$ diphenyl $\left(\mathrm{C}_{12} \mathrm{H}_{10}\right)$. On the other hand, since the molten salts based on sodium and potassium nitrates have a good exchange coefficient and a good thermal inertia, which allows them to store heat, they are used in the present study.

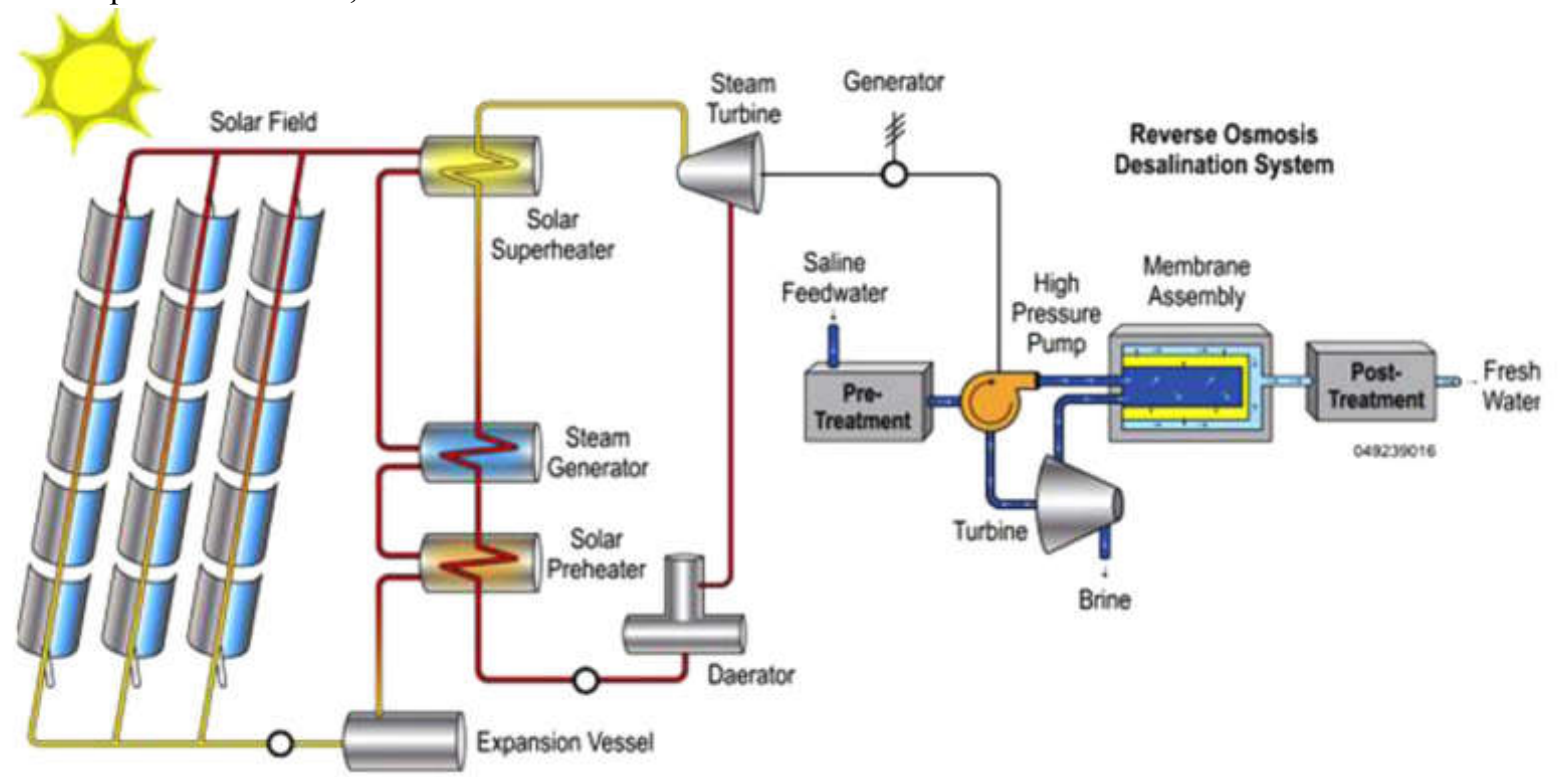

Figure 1. Schematic diagram of the Rankine cycle with solar field powering RO desalination system [8]

\section{System simulation}

\section{III.1. Reverse osmosis (RO)}

The approach used to obtain the electrical power required to run ten (10) reverse osmosis modules is done using the ROSA software.

The ROSA 9.1 software is the latest version, used in the analysis to determine membrane performance and energy requirements for desalination [6].

ROSA can be used to finalize and optimize the design of an installation, provide details for the selection of a feed pump and provide information for post-processing requirements [6].

The ROSA program has four input pages, a report page and a cost analysis page. The six tabs are:

1. Project Information.

2. Feed water data.
3. Scaling information.

4. System Configuration.

5. Report.

6. Cost analysis.

Table 1 shows the main parameters of feed water Table 1. Supply water settings

\begin{tabular}{|l|l|}
\hline \multicolumn{2}{|c|}{ Number of modules $=10$} \\
\hline Seawater salinity & $36132 \mathrm{mg} / \mathrm{l}$ \\
\hline Temperature & 18.8 \\
\hline $\mathrm{PH}$ & 8.5 \\
\hline
\end{tabular}

Figure 2 shows the configuration of the system, in the case of a single module or there are 246 pressure tubes, each tube equipped with 7 membranes (1722 membranes in total). The type of membrane is SW $30 \mathrm{HR}-380$. The permeate flow rate is $20,000 \mathrm{~m}^{3} / \mathrm{d}$ and the conversion rate is $47 \%$. 


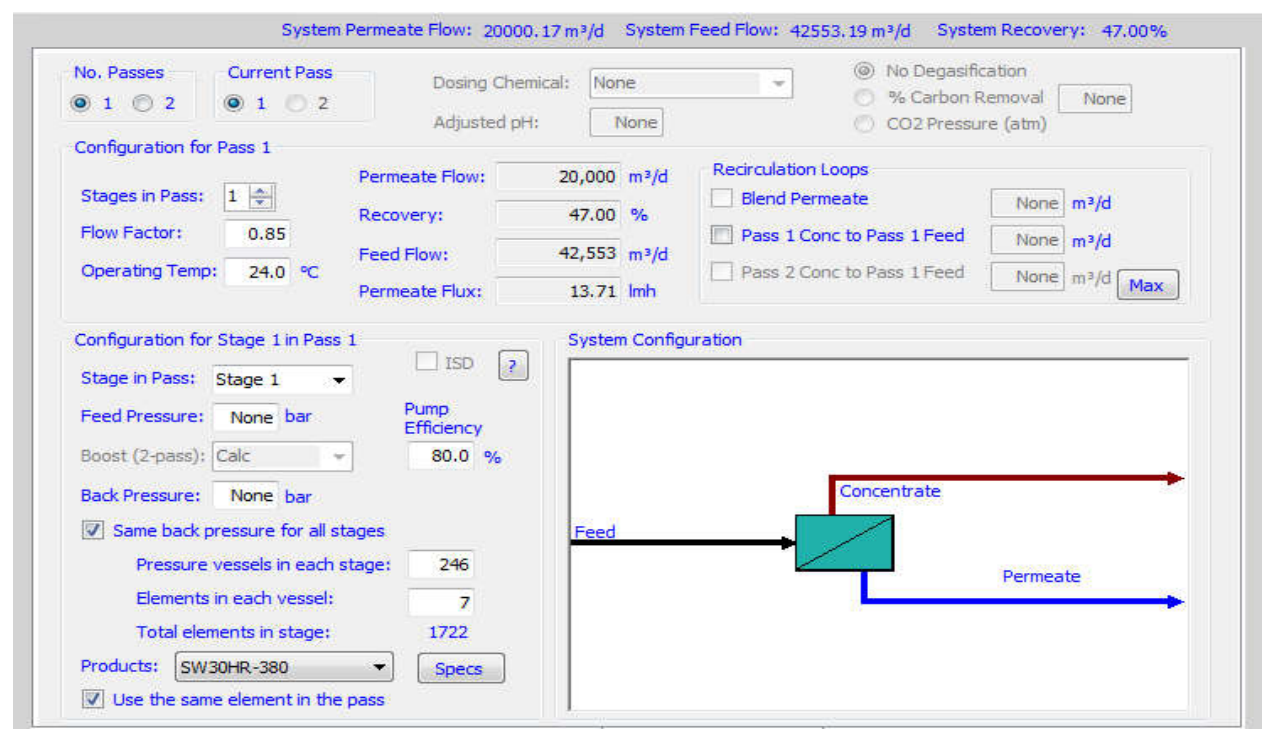

Figure 2. The configuration of the reverse osmosis system on ROSA

\section{III.2. Rankine cycle with solar field}

After having completed the first step concerning the reverse osmosis module and the definition of the power necessary to operate the reverse osmosis desalination unit, we will proceed to the next step, which concerns the dimensioning of the CSP plant in order to provide a power supply for the reverse osmosis unit. We used another technical-economic software to determine the technical characteristics and costs of the CSP system, as well as the performance analysis of the parabolic cylindrical CSP plant.

In this part, we will make a simulation of a CSP plant, whose heat transfer fluid is thermal oil (Therminol VP1), this plant is tested for the Ain Témouchent site, the nominal power of this plant is 40.7 MWe. The System Advisor Model (SAM) code was used to simulate the annual behavior of the CSP plant at the time scale. SAM predicts the dynamic behavior of the parabolic trough.

The System Advisor Model (SAM) software is a software that performs cost and performance analysis of solar installations. This software was developed by the National Renewable Energy Laboratory (NREL), Sandia's national laboratories in partnership with the United States Department of Energy (DOE), and the Solar Energy Technology and Program (SETP). It has been designed to facilitate decision-making for those involved in the renewable energy industry [5].

The empirical model of a CSP modeling plant is identical to the physical model, only it uses a set of curve fitting equations derived from the regression analysis of the measured data from SEGS (Solar Energy Generating Systems) projects in the southwestern United States, is shown in Figure 3.

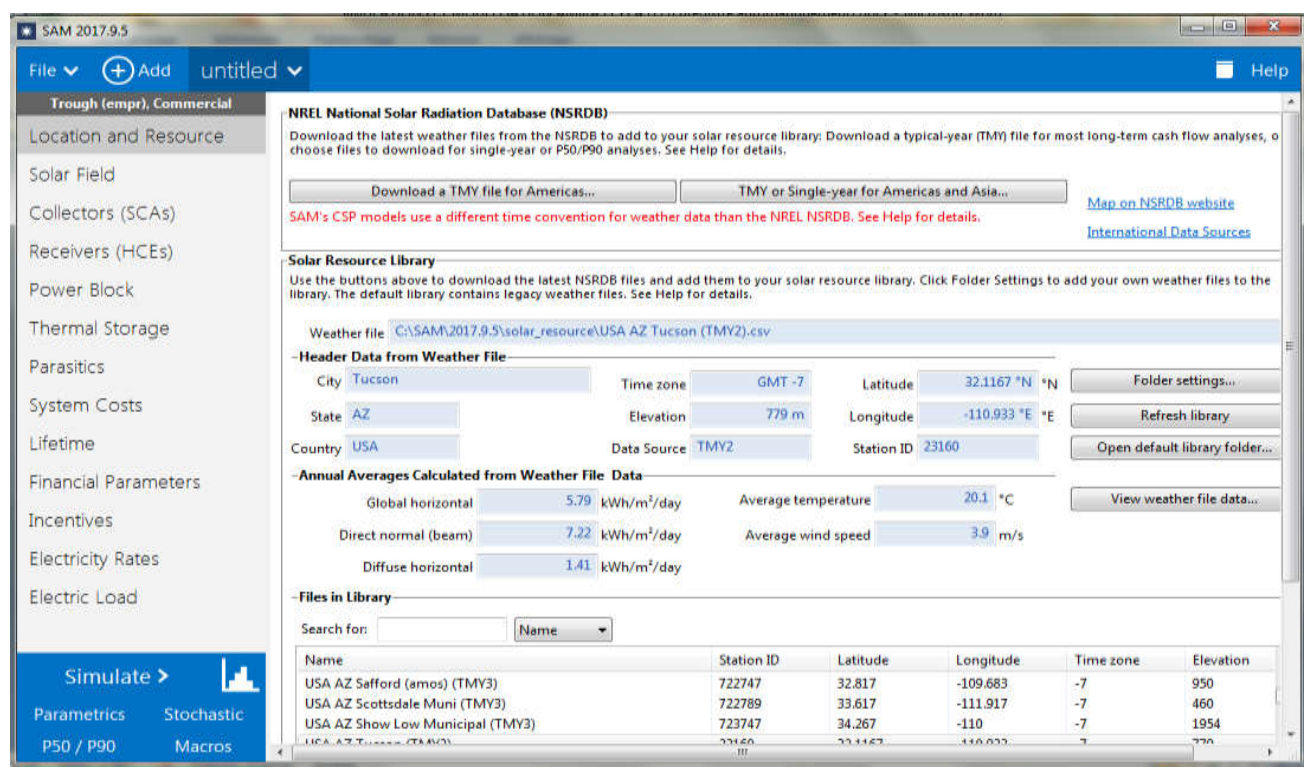

Figure 3. The CSP plant in SAM program 
The parameters concentrating the different components of the installation are:

1-Solar Field

2-Collectors (SCAs)

3-Receivers (HCEs)

4-Power Block

5-Thermal Storage
Figure 4a Shows the solar radiation, the most extreme estimations of solar radiation was $1000 \mathrm{~W} \cdot \mathrm{m}^{-2}$. Figure $4 . \mathrm{b}$ shows the change in ambient temperature and Figure $4 \mathrm{c}$ shows the wind speed during the year for the selected site. Note that the maximum and minimum temperature recorded is equal to $37^{\circ} \mathrm{C}$ and $1^{\circ} \mathrm{C}$ respectively and we note that the maximum wind speed is $15 \mathrm{~m} / \mathrm{s}$.

\section{Results and discussion}

IV.1. Meteorological data

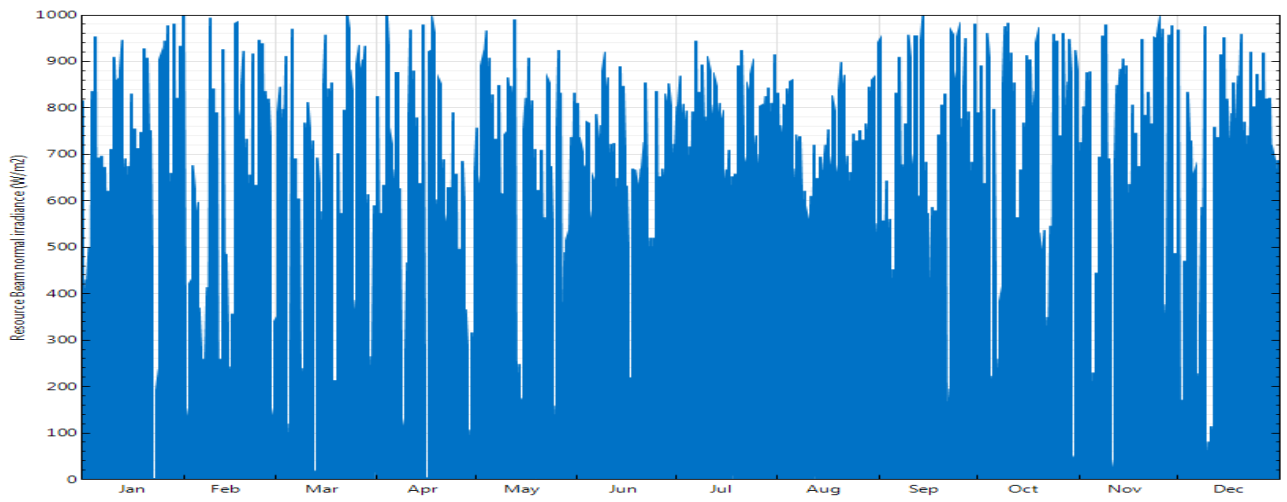

Figure $4 \mathrm{a}$. Shows the solar radiation
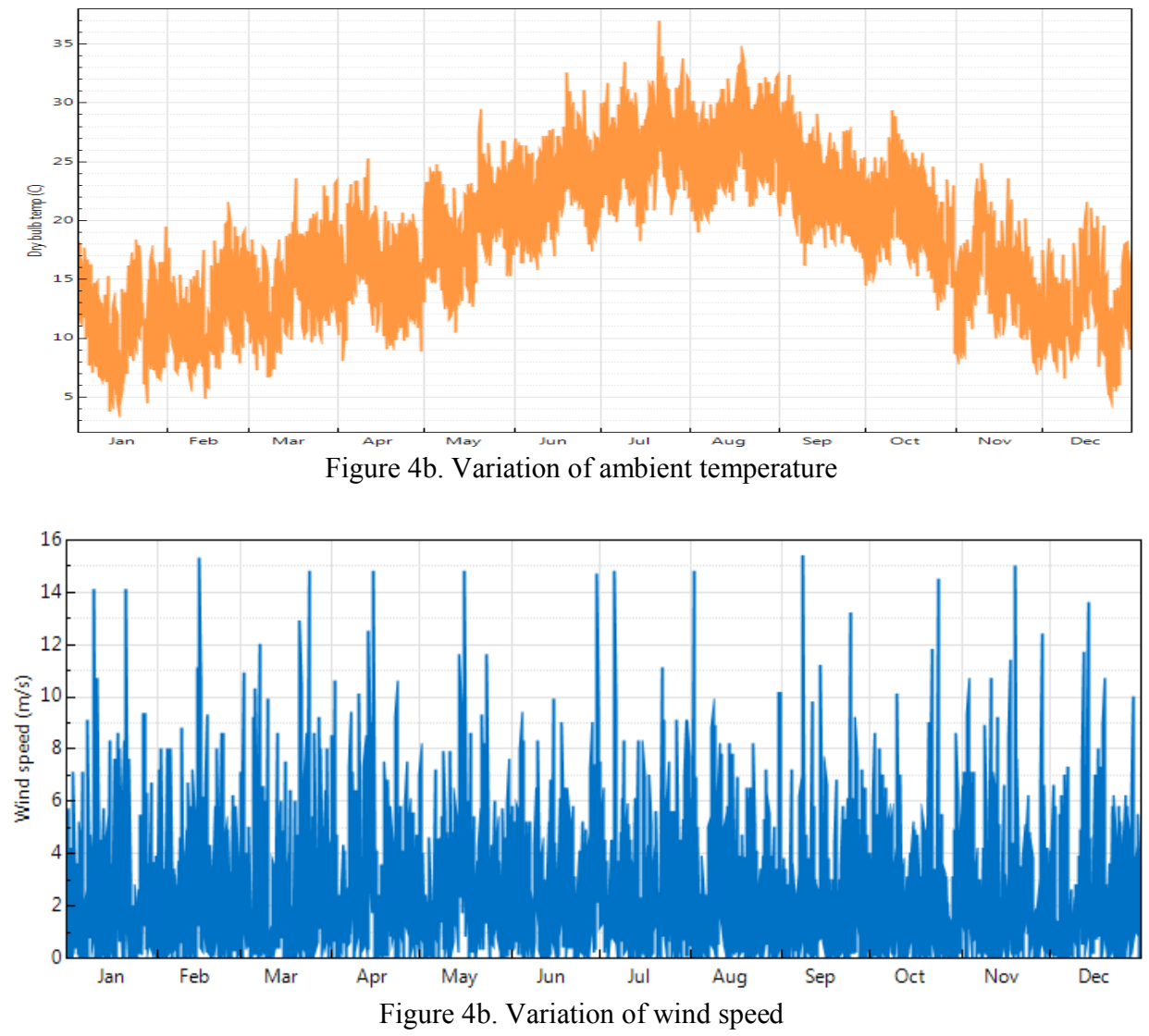


\section{IV.2. Reverse osmosis}

After introducing, the previous data into the ROSA code. The simulation results shown in Table 2, we note that the electrical power of a single module is $4101 \mathrm{KW}$; this is consistent with the manufacturer's data that this power must be between $3900 \mathrm{~kW}$ and $4300 \mathrm{KW}$. Thus, the energy consumption of the system is $4.92 \mathrm{KWh} / \mathrm{m} 3$.

Table2: RO system details

\begin{tabular}{|l|l|}
\hline Parameter & Value \\
\hline Feed flow rate $[\mathrm{m} 3 / \mathrm{j}]$ & 42553.19 \\
pressure brine $[\mathrm{bar}]$ & 66.61 \\
brine flow rate $[\mathrm{m} 3 / \mathrm{j}]$ & 22553.02 \\
pressure Permeate $[\mathrm{bar}]$ & 65.20 \\
Permeate flow rate $[\mathrm{m} 3 / \mathrm{j}]$ & 20000.17 \\
salinity $[\mathrm{mg} / \mathrm{l}]$ & 277.51 \\
The power $[\mathrm{kw}]$ & 4101.57 \\
Specific energy $[\mathrm{kwh} / \mathrm{m} 3]$ & 4.92 \\
\hline
\end{tabular}

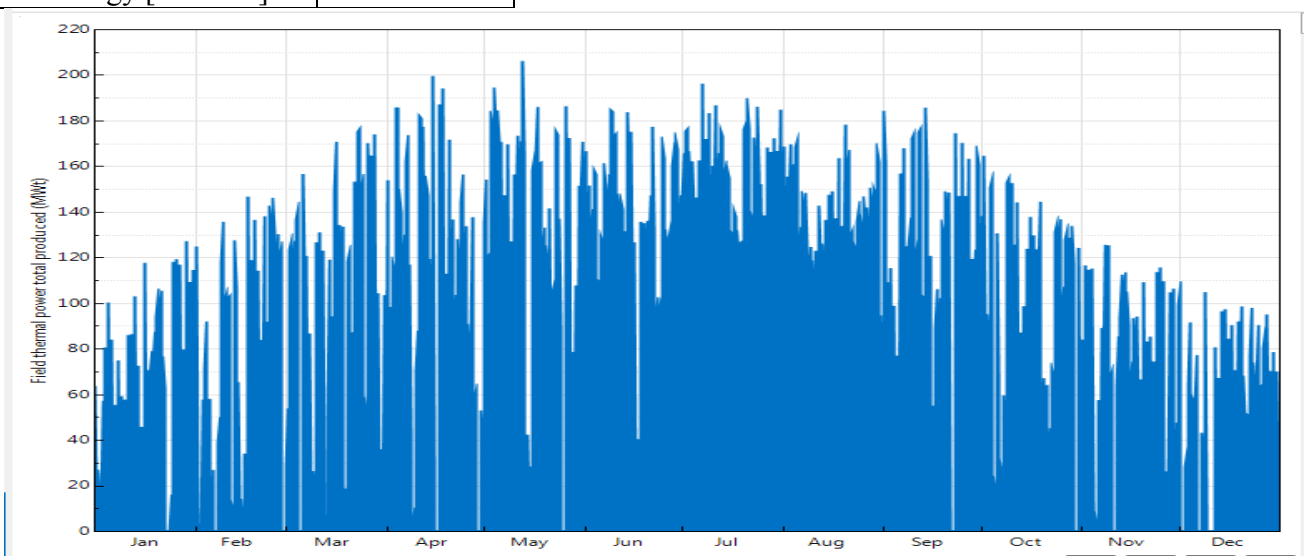

Figure 5. Total thermal power produced during the year (MWt)

\section{IV.3.2. Electrical power produced by the plant}

Figure 6 shows the hourly variation in the net power generated during the year. Note that the power is varied

\section{IV.3. System performance of CSP plan}

\section{IV.3.1. Thermal power produced by the solar cylindro-parabolic field}

Figure 5 shows the total heat output produced during the year. We note that the thermal power during the month of May has the maximum that is 208MWth, and the minimum value of the thermal power recorded during the month of April, which equals $6 \mathrm{MWth}$.

between $47 \mathrm{MWe}$, and $23.8 \mathrm{MWe}$. It is observable that the power produced is proportional to the incident direct radiation on the solar reflectors.

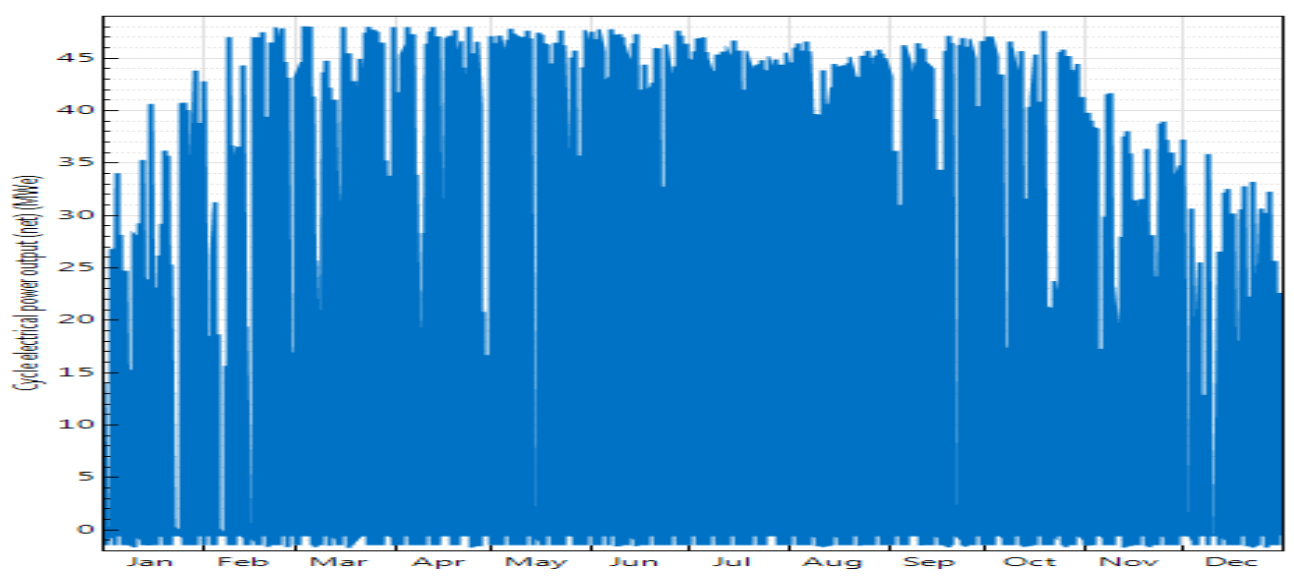

Figure 6. System power generated during the year (KWe) 


\section{IV.3.3. Power of CSP plant}

As can be seen in the graphs above that: The maximum thermal power absorbed was estimated at 12 Mwt as well as the maximum electrical output power (net) was estimated at $4.5 \mathrm{Mwe}$, and the maximum electrical power of production (gross) was estimated at 4.8 Mwe and Incident of maximum thermal power on the ground was estimated at $30 \mathrm{Mwt}$.its maximum thermal loss of the reservoir was estimated at $0 \mathrm{Mwt}$ and TES Maximum thermal energy in storage was estimated at 4 Mwt.

\section{IV.3.4. Energy generated and thermal energy in storage}

The energy generated by each month and the thermal energy for storage illustrated in Figure 7. It can be seen that the maximum energy was generated during the
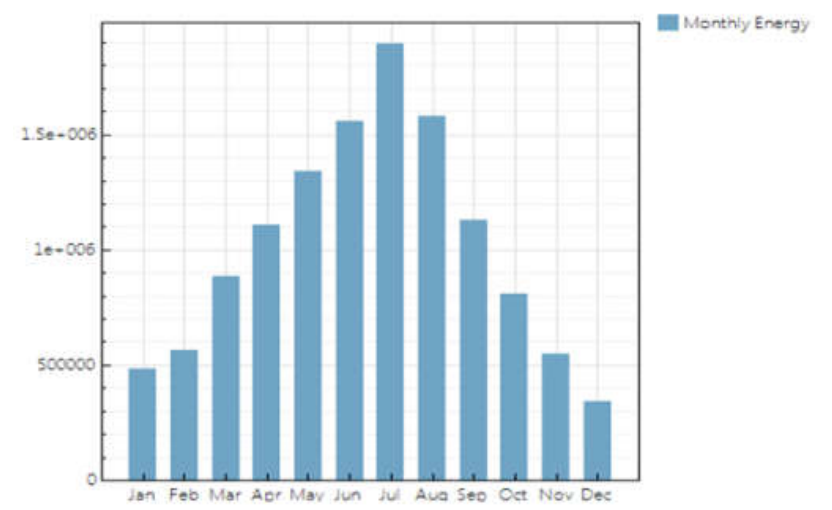

month of July (1900 MWh) with the maximum energy stored (118 MWh).

\section{IV.3.5. Field HTF temperature hot and cold header}

The heat transfer fluid (HTF) flows from the cold reservoir to the hot reservoir, the minimum temperature of the cold header inlet has reached a value of $160{ }^{\circ} \mathrm{C}$, and the maximum temperature obtained at the header outlet hot is $4000 \mathrm{C}$. The variation of the temperature of the hot and cold header input is shown in the Figure 8.

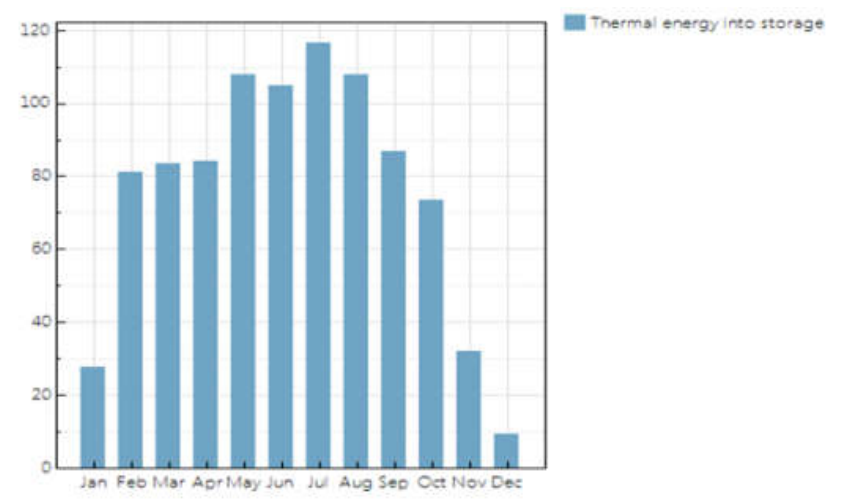

Figure 7. Monthly energy generated and thermal energy in storage (MWh)
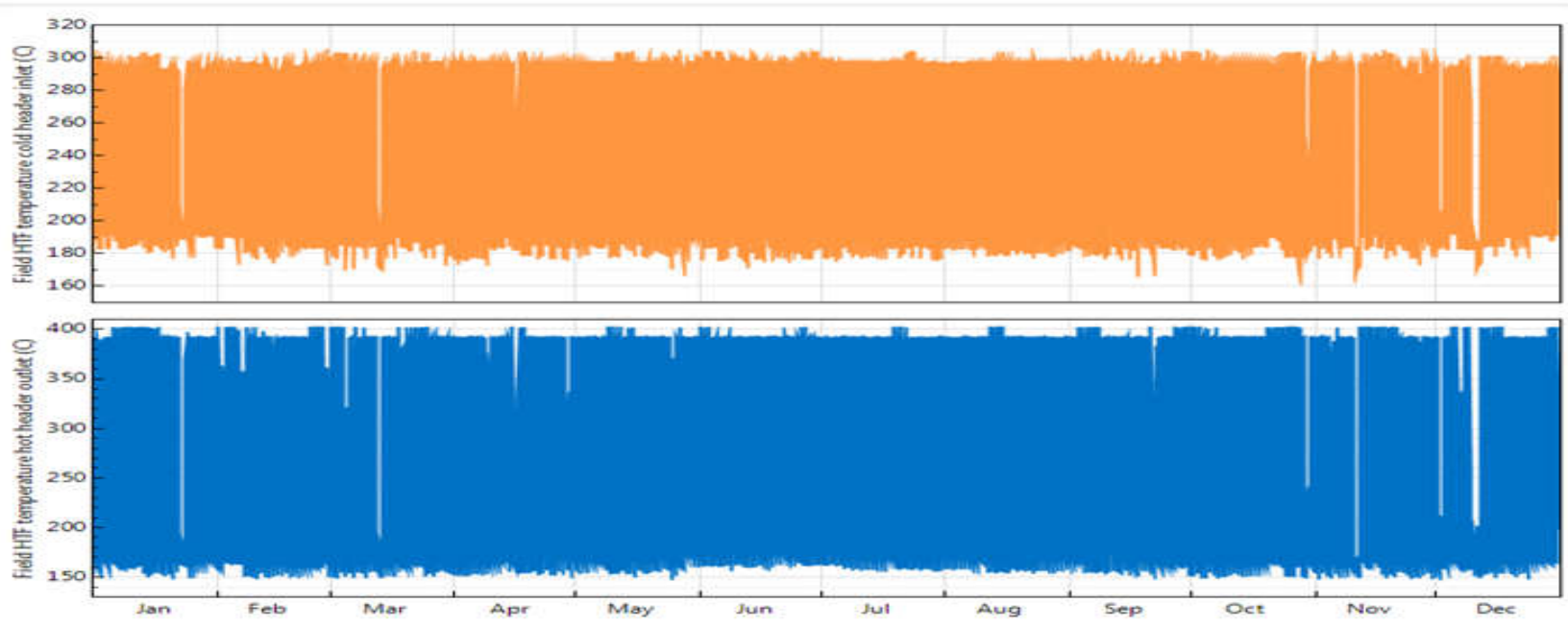

Figure 8. Field HTF temperature hot and cold header 

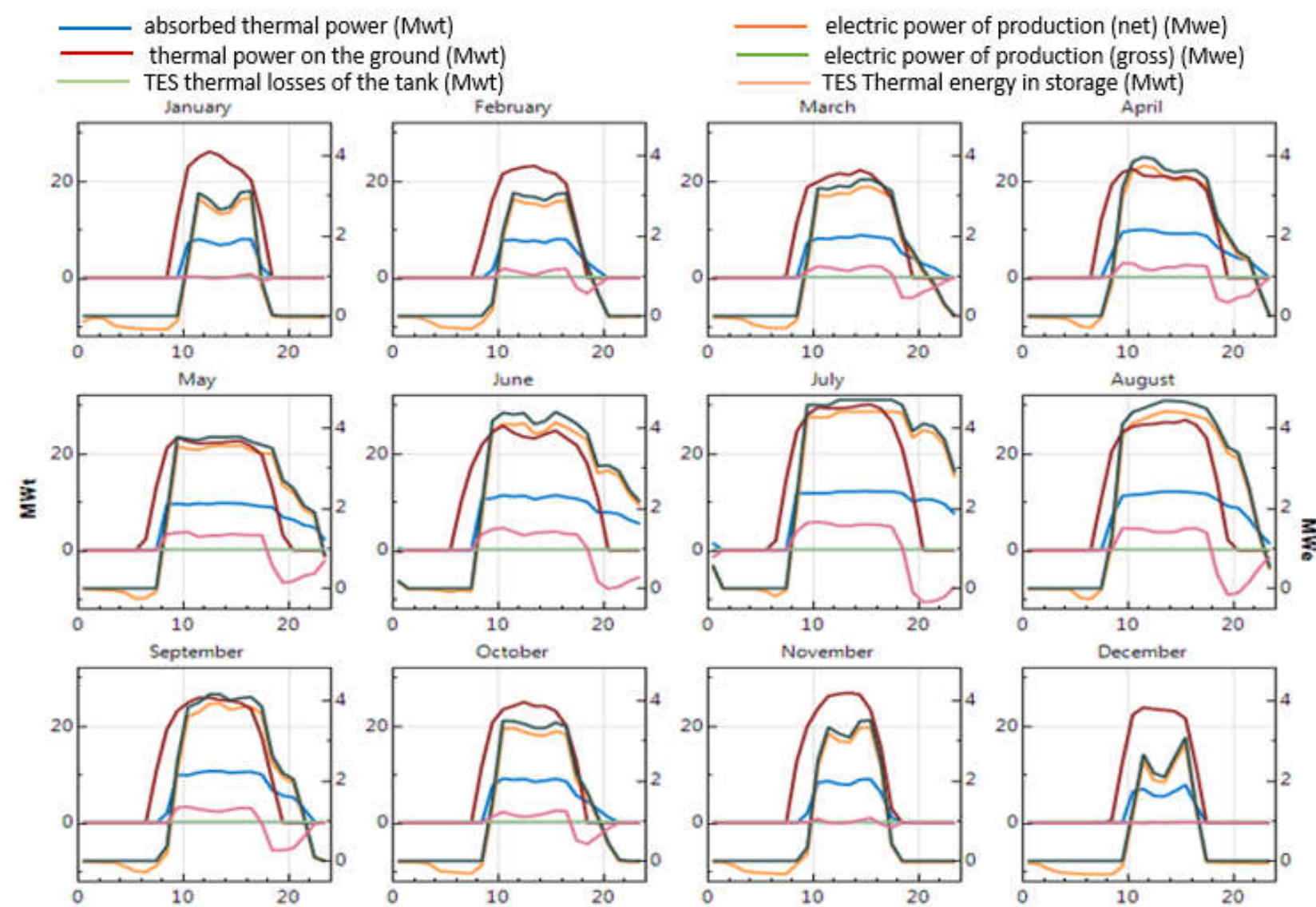

Figure 9. Absorbed thermal power (Mwt) and field power (Mwt), gross and net electric power (Mwe), TES thermal losses from the tank (Mwt) and in storage (Mwt)

\section{IV.3.6. TES HTF, hot and cold tanks volume}

volume is $1000 \mathrm{~m}^{3}$ and the maximum cold tank HTF volume is $1200 \mathrm{~m}^{3}$ as shown in Figure 9 and Figure 10.

For power generation after sunset, the HTF fluid should be stored in the storage tank for a storage capacity of 8:00 h. The total HTF maximum thermal energy storage (TES) is $1300 \mathrm{~m}^{3}$, the maximum hot tank HTF

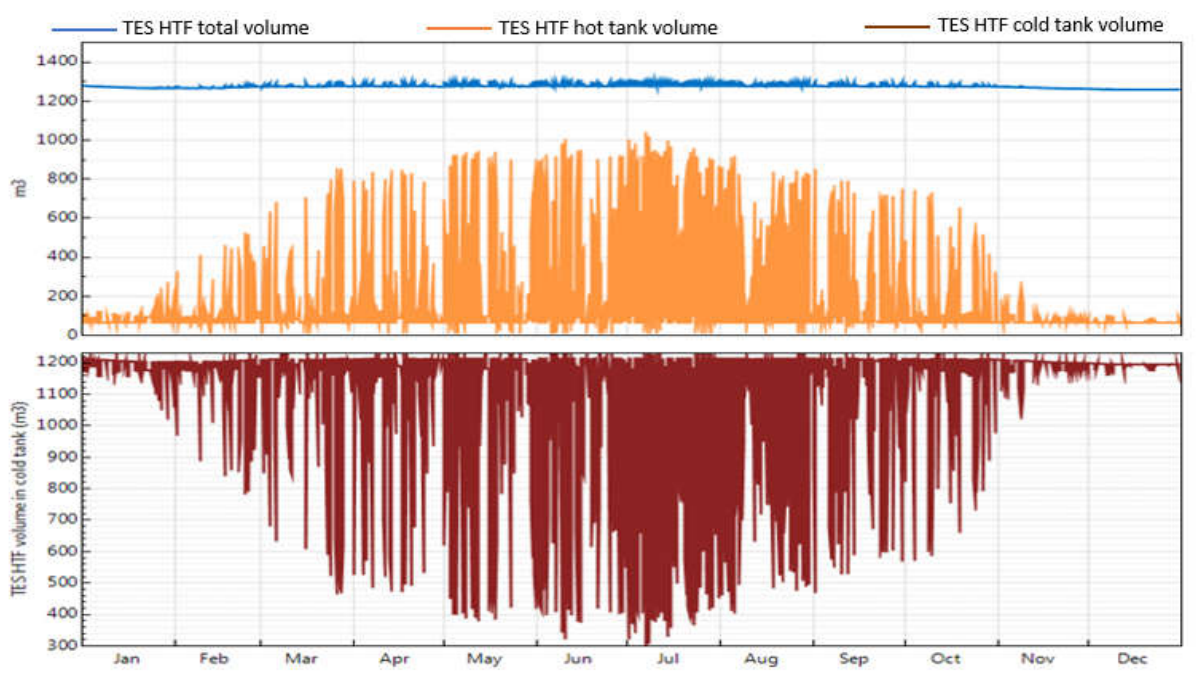

Figure 10. TES HTF total volume, hot and cold tanks volume 
The simulation is carried out using the SAM software, the technical characteristics of the CSP system are shown in Table 3 and the system costs are shown in Table 4.

Table 3: Technical characteristics of CSP system

\begin{tabular}{|l|l|l|}
\hline & The variables & Values \\
\hline Collector & Reflective Opening Area $\left[\mathrm{m}^{2}\right]$ & 817.5 \\
& Opening width, total structure [m] & 5.75 \\
& Length of collector assembly [m] & 150 \\
& Number of modules per assembly [-] & 12 \\
& Average length of the surface at the focal length [m] & 2.11 \\
& Distance between assemblies [m] & 1 \\
\hline Receiver & Inside diameter of absorber tube [m] & 0.076 \\
& Outer diameter of absorber tube [m] & 0.08 \\
\hline The solar & Line spacing [m] & 15 \\
field & Irradiation [W/m $\left.{ }^{2}\right]$ & 950 \\
& Thermal field production $[\mathrm{MW}]$ & 23.5613 \\
& Solar Field Area (acres) & 25 \\
& Total Area (acres) & 35 \\
\hline
\end{tabular}

Table 4. CSP system costs.

\begin{tabular}{|l|l|}
\hline The costs & Values \\
\hline Site Improvements (\$) & 981000 \\
Solar field (\$) & 5886000 \\
HTF system (\$) & 2354400 \\
Storage $(\$)$ & 6125950 \\
Total direct cost $(\$)$ & 22120782 \\
Total Indirect Cost $(\$)$ & 3672293 \\
Total cost of installation $(\$)$ & 25793022 \\
Total cost of the facility per capacity $(\$ / \mathrm{kW})$ & 6833 \\
\hline
\end{tabular}

\section{Conclusion}

This article focuses on the techno-economic modeling of a cylindro-parabolic power plant to generate the electrical energy required for desalination by reverse osmosis. The results show that:

- The electrical power of a single module is $4101 \mathrm{KW}$; this is consistent with the manufacturer's data that this power must be between $3900 \mathrm{~kW}$ and $4300 \mathrm{KW}$. Thus, the energy consumption of the system is 4.92 $\mathrm{KWh} / \mathrm{m}^{3}$.

- Thermal power produced by the solar cylindroparabolic field during the month of May has the maximum that is $208 \mathrm{MW}$ th and the minimum value during the month of April, which equals $6 \mathrm{MWth}$.

- Electrical power produced by the plant varied between 47MWe, and 23.8MWe

- The maximum energy was generated during the month of July (1900 MWh) with the maximum energy stored (118 MWh).

- The minimum temperature of the cold header inlet has reached a value of $160{ }^{\circ} \mathrm{C}$, and the maximum temperature obtained at the header outlet hot is 400 ${ }^{0} \mathrm{C}$.

- Total cost of the facility per capacity is $6.833 \$ / \mathrm{kW}$

\section{Acknowledgements}

The authors gratefully acknowledge support from Smart Structure Laboratory of University Center Belhadj Bouchaïb, Ain Témouchent (Algeria).

\section{References}

[1] C. GALUS, "Les techniques de dessalement de l'eau de mer prennent de l'essor, extrait du Monde, 2000.

[2] Deepak Bishoyi, K. Sudhakar, "Modeling and performance simulation of 100 MW LFR based solar thermal power plant in Udaipur India", Resource-Efficient Technologies, 2017, doi: 10.1016/j.reffit.2017.02.002

[3] L. Martin, M. Mariano, "Optimal year-round operation of a concentrated solar energy plant in the south of Europe". Appl. Therm. Eng. 2013, Vol. 59, pp. 627-633.

[4] L.I Garcia, J.L Alvarez, D. Blanco, "Performance model for parabolic trough solar thermal power plants with thermal storage: Comparison to operating plant data". Sol. Energy, 2011, Vol. 85, pp. 2443-2460.

[5] Nate Blair, "System Advisor Model, SAM2014.1.14: General Description", National Renewable Energy Laboratory, 2014.

[6] Ahmed Remlaoui, Driss Nehari, Abderrahmane Elmeriah Reverse Osmosis System Analysis, ROSA9.1-9/21/2013: General Description, Dow Water \& Process Solutions. 2013. 
[7] T Mezher, H Fath, Z Abbas, A Khaled. "Techno-economic assessment and environmental impacts of desalination technologies". Desalination, 2011, Vol. 266, No1, pp. 263-73.

[8] A. Al-Karaghouli, LL. Kazmerski. "Energy consumption and water production cost of conventional and renewableenergy-powered desalination processes". Renew Sustain Energy Rev, 2013, Vol. 24, pp. 343-56.

[9] Shiva Gorjian, Barat Ghobadian. "Solar desalination: A sustainable solution to water crisis in Iran". Renewable and Sustainable Energy Reviews, Vol. 48, 2015, pp. 571584. 